Milan Lazarević, pukovnik

Jovan Bajcetic,

potporucnik, dipl. inž. Vojna akademija - Odsek logistike,

Beograd

\section{POREĐENJE KARAKTERISTIKA I} MOGUCNOSTI BUDUCEG SERVISA U MIKROTALASNOM PODRUCJU I MOBILNIH SISTEMA TRECE GENERACIJE

UDC: $621.396 .21: 621.3 .014 .2$

Rezime:

Znacaj i izuzetno brz razvoj telekomunikacija namece neprekidno izucavanje i primenu novih servisa $i$ novih postupaka integracije $i$ komutacije u njemu. Od komercijalnih radio-servisa koji su trenutno dostupni u našoj zemlji, najveci deo je iz sistema javne mobilne telefonije. $U$ radu je prikazana organizacija $i$ nacin funkcionisanja mobilnog komutacionog sistema i njegovo mesto i znacaj u sistemu veze Srbije. De taljno je obraden WiMAX (World Interoperability for Microwave Access) servis mobilne telefonije i analizirane njegove prednosti i nedostaci u odnosu na mobilni servis $3 G$ (trece generacije). Predložena je implementacija WiMAX-a u savremen sistem telekomunikacija.

Ključne reči: mobilni komutacioni sistemi, WiMAX servis mobilne telefonije, mobilni servis $3 G$, implementacija WiMAX-a u sistem telekomunikacija.

\title{
THE COMPARISION OF CHARACTERISTICS AND OPPORTUNITIES OF FUTURE SERVICE IN MICROWAVE BAND AND MOBILE SYSTEMS THIRD GENERATION
}

Summary:

The importance and very quick development of telecommunications ask for endless research and applying new services and new methods of integration and switching in it. Among commercial radio services that are at the moment accessible in our state, the most significant part is from public mobile telephony system. In this work we presented organization and way of functioning of mobile switching system and their place and importance in Serbian system of communications. WiMAX service of mobile telephony is processed in details and advantages and disadvantages versus $3 G$ mobile service are analyzed. The suggestion of implementation of WiMAX in modern system of telecommunications is given.

Key words: mobile switching systems, WiMAX service of mobile telephony, $3 G$ mobile service, implementation of WiMAX in system of telecommunications.

\section{Uvod}

Sistem veza jedan je od servisa za zadovoljavanje potreba iz oblasti nauke, kulture, obrazovanja, zdravstva i svih drugih oblasti života. Putem satelita i internet mreže sve navedene potrebe mogu se ostvarivati ulaskom u medunarodni sistem veze. Sve brži protok podataka omogucuje prenos informacija u realnom vremenu [1].
Manje razvijene zemlje su u ogromnom zaostatku u pogledu opštedostupnih komunikacionih sistema, pogotovo onih $\mathrm{u}$ okvirima prenosa informacija radio-putem. Razvoj savremene tehnologije uvek je bilo teško pratiti. Svako uvodenje nove tehnologije u komercijalnu upotrebu zahteva, pored skupe opreme, i veoma skupu licencu za korišcenje. Od komercijalnih radioservisa koji su trenutno dostupni u našoj 
zemlji najveci deo proizilazi iz sistema javne mobilne telefonije. Pored ovakvog tipa ostvarivanja bežicnih komunikacija, u buducnosti se otvara mogucnost za neki drugi tip ostvarivanja radio-veza koji može pružiti vecu finansijsku dobit i prednost $u$ vidu kvaliteta servisa koji pruža. Taj potencijalni sistem je mobilni WiMAX, buduci servis u mikrotalasnom podrucju.

Dok se mobilni WiMAX standard razvijao, proizvodaci su uveliko unapredivali opremu proizvedenu na osnovu standarda 802.16e. Mobilni WiMAX vec je postao dostupan za komercijalnu upotrebu u nekoliko zemalja zapadne Evrope. Postavlja se pitanje da li ce u odnosu na $3 \mathrm{G}$ mobilnu telefoniju ovaj tip prenosa signala biti u prednosti ili ne. Odgovor na ovo pitanje dobice se uporednom analizom jednog i drugog bežicnog sistema. U ovom radu predstavice se karakteristike jednog i drugog sistema radi njihovog uporedenja. Veci deo rada posvecen je mobilnom WiMAX sistemskom profilu, cije su osnovne karakteristike u ovdašnjim krugovima manje poznate.

Pretpostavka je da ce se u okviru dugorocnog plana telekomunikacionih usluga u Srbiji, pored trenutno aktuelnih pilot-programa $3 \mathrm{G}$ mobilne telefonije, šira javnost vrlo brzo upoznati sa mogucnostima mobilnog WiMAX-a. Na taj nacin bice premošcen jaz izmedu sadašnje, donekle zaostale tehnologije u sistemu javne mobilne telefonije i najmodernijih komercijalnih radio-sistema.

\section{Sistem javne mobilne telefonije}

Sistem javne mobilne telefonije deo je telekomunikacionog sistema koji, $u$ poredenju sa fiksnim sistemom, ima brzu i jednostavnu instalaciju, a ulaganja su postepena i relativno mala. Savremene javne mobilne telekomunikacije omogucavaju ne samo mobilnost korisnika, vec i veliki broj usluga i korišcenje raznih servisa. Mobilni sistemi ubrzavaju izgradnju telefonskog sistema u nerazvijenim zemljama i dopunjavaju razvoj postojece fiksne telefonske mreže.

Zacetak digitalne mobilne telefonije na prostorima Srbije vezuje se za uvodenje globalnog sistema za mobilne komunikacije - GSM (Global System for Mobile Communications). Digitalna javna mobilna telefonska mreža GSM $900 \mathrm{u} \mathrm{Sr}$ biji je puštena u rad 1996. godine. Usluge mobilnih telekomunikacija u svetu i Srbiji danas predstavljaju osnovne personalne telekomunikacione usluge [1].

Razvijenost globalne mobilne mreže ogleda se u cinjenici da postoji 296 GSM mreža u 114 zemalja u svetu sa oko 138 miliona korisnika. GSM trenutno zauzima $49 \%$ svetskog tržišta, a u Nemackoj je najveci broj korisnika ovog sistema. „TIM“ (Italija) je najveca GSM mreža, sa oko 15 miliona korisnika. Pored GSM mobilnih sistema, neke evropske zemlje podigle su svoje sisteme na nivo trece generacije mobilne telefonije. I u Srbiji su sada omoguceni protoci podataka koji omogucavaju sigurnu vezu putem interneta, uz pomoc opšteg radio-servisa baziranog na paketskoj komutaciji GPRS-a (General Packet Radio Service).

\section{Karakteristike mobilnog globalnog sistema (GSM)}

Globalni sistem mobilne komunikacije ima radio-kanal šrine $200 \mathrm{kHz}$ sa osam vremenskih slotova od $0,577 \mathrm{~ms}$, ukupno 125 dupleksnih radio-kanala. 
Frekvencijski opseg na kojem se ostvaruje veza u mobilnoj telefoniji je od 890 do $960 \mathrm{MHz}$, i to:

- uzlazne veze (uplink), mobilna $\rightarrow$ bazna stanica, 890 do $915 \mathrm{MHz}$,

- silazne veze (downlink), bazna $\rightarrow$ mobilna stanica, 935 do $960 \mathrm{MHz}$.

Velicina celija, odnosno prostor $u$ kojem se omogucuje veza u okviru jedne bazne stanice, krece se od maksimalno 35 $\mathrm{km}$ do minimalno $1 \mathrm{~km}$ u precniku. Tipicne vrednosti su oko $10 \mathrm{~km}$ u ruralnoj sredini, odnosno 3 do $5 \mathrm{~km} \mathrm{u}$ urbanoj sredini.

Sistem ima visoku opštu imunost na smetnje. Karakteriše ga brzo preuzimanje mobilne stanice koja se krece iz jedne u drugu celiju, odnosno prelazi na lokaciju druge bazne stanice (handover). Poseduje veliki broj razlicitih korisnickih radio-servisa i usluga: za prenos govora, za prenos podataka $\mathrm{i}$ dodatne informacione servise. Ima dobru frekventnu rasprostranjenost, što omogucava da dve celije mogu koristiti istu grupu frekvencija ukoliko izmedu njih postoji dovoljna udaljenost (frequncy recause). Omogucava prelazak mobilne stanice iz jedne nacionalne mobilne mreže $u$ drugu nacionalnu mobilnu mrežu - roming (Roaming). To se, pre svega, odnosi na sve širu dostupnost mobilnih usluga uopšte - na velikom delu teritorije, u svako vreme $\mathrm{i}$ skoro u svim uslovima. Rasprostranjene su, pre svega, govorne interaktivne medukorisnicke usluge, ali sve više i druge usluge koje omogucavaju pristup internet sadržajima velikim brzinama.

Mobilna stanica (MS) jeste elemenat mobilnog sistema preko kojeg korisnik pristupa mreži. Sastoji se od mobilne opreme - aparata (Mobile Equipment) i SIM kartice (Subscriber Identity Module). Svaka MS ima svoj broj identifikacije [1]. Nova generacija mobilnih uredaja i sistem $3 \mathrm{G}$ (treca generacija mobilne telefonije) omogucavaju bežicni pristup internetu brzinama koje dozvoljavaju simultani prenos pokretne slike, glasa i podataka.

Bazna stanica RBS (Radio Base Station) kljucni je elemenat globalnog mobilnog sistema. To je jedinstveni naziv za lokaciju na kojoj se nalaze primopredajni radio-uredaji i odgovarajuca telekomunikaciona oprema, koja služi za povezivanje bazne stanice sa ostalim delovima javne mobilne telekomunikacione mreže. Njihov domet krece se od tridesetak kilometara u ruralnom do nekoliko kilometara u gradskom podrucju.

Kontrolor baznih stanica, BSC (Base Station Control) zasebni je elemenat koji kontroliše više baznih stanica (RBS). On vrši administraciju celije i njenih radio-kanala tako što neprestano sakuplja podatke o statistici broja poziva i uspešnosti prebacivanja poziva $u$ drugi radio-kanal RBS.

Komutacioni sistem (Switching System) omogucava prenos poziva, podataka, govora, paketski prenos, kontrolu saobracaja, analizu brojeva, tarifiranje, statistiku pozivanja i ukljucivanje u globalnu mrežu (internet). Pored mobilne i bazne stanice mobilni komutacioni sistemi imaju sledece elemente:

- komutacioni centar mobilnih servisa, MSC (Mobile Switched Centre), koji obavlja celu komutaciju, signalizaciju i funkcije obrade za mobilne stanice;

- sistem za registrovanje i servisiranje na odredenoj lokaciji, VLR (Visitor Location Register);

- centar koji obavlja funkcije sigurnosti, AUC (Authentication Centre); 
- centar za bazu podataka zadužen za proveru ispravnosti MS-a ( Equipment Identity Register);

- deo sistema za komutaciju podataka u okviru GSM-a, GIWU (GSM Interworking Unit).

U Srbiji je krajem 2005. godine oko 3,6 miliona ljudi koristilo usluge mobilnih telekomunikacija, što znaci da je mobilna telefonija dostigla nivo od oko $46 \%$ korisnika (u odnosu na nominalan broj stanovnika od 7,5 miliona). S obzirom na to da je u razvijenim zemljama zapadne Evrope zastupljenost mobilne telefonije premašila brojku od $50 \%$ (Nemacka 71,6\%, Austrija 84,0\%, Italija 92,1\%), a takode i u zemljama kao što su Hrvatska $54,2 \%$, Madarska 74,1\%, Ceška 87,1\%, Slovenija $87,2 \%$, jasno je da na prostoru Srbije treba ocekivati povecanje broja korisnika mobilnih telekomunikacija [1].

Sem osnovnog servisa, u mobilnoj telefoniji Srbije postoje i drugi servisi: servis za mobilnu komutaciju putem poruka, SMS (Switched Messaging Service); virtualna privatna mreža, VPN (Virtual Private Network); servis multimedijalnih poruka, MMS (Multimedia Messaging Service); protokol bežicnih aplikacija, WAP (Wireless Application Protokol); Internet; Roaming; Voice Mail. Postojeci operatori mobilne telefonije istovremeno obezbeduju širokopoja sni pristup internetu korišcenjem tehnologija za opšti radio-servis baziran na paketskoj komutaciji, GPRS (General Packet Radio Service) i poboljšani protok podataka za GSM evoluciju, EDGE (Enhanced Data Rates for GSM Evolution) koji se u našoj zemlji vrlo sporo uvodi u korišcenje.

U celom svetu od skoro je pocelo svestrano uvodenje $3 \mathrm{G}$ mobilnih sistema kao naslednika EDGE tehnologije. On je pokazao veliku komercijalnu upotrebljivost na osnovu široke palete servisa koje korisnici eksploatišu iskljucivo na osnovu višestrukog pristupa kodnom raspodelom kanala, CDMA (Code Division Multiple Access).

Dve su osnovne varijante CDMA koje se danas koriste. To su višestruki pristup širokopoja snom kodnom raspodelom kanala, WCDMA (Wide Code Division Multiple Access) na bazi dupleks frekvencijske raspodele kanala (FDD Frequency Division Duplex) sa širinom kanala od $5 \mathrm{MHz}$ i CDMA2000, na istoj bazi, sa kanalima širine 1,25 MHz. Da bi se povecao kapacitet downlinka $3 \mathrm{G}$ sistema, ugraden je dodatak u vidu pristupa paketima podataka downlinkom velike brzine (HSDPA-High Speed Downlink Data Packet Access) za WCDMA. Kasnije poboljšanje pristupom paketima podataka uplinkom velike brzine (HSUPA - High-Speed Uplink Data Packet Access) povecava kvalitet uplinka. Iste promene i poboljšanja ucinjena su za CDMA2000, gde novi standard EVDO (EVDO-EVolution Data Optimized) donosi znacajan napredak saobracaju. Novi sistem 3G takode koristi poboljšanje WCDMA vezano za MIMO (Multiple Input Multiple Output) sa HSDPA.

\section{Mobilni sistem WiMAX}

Mobilni WiMAX (World Interoperability for Microwawe Access) predstavlja prilicno dobro rešenje za mobilne i fiksne ucesnike na šrokom prostoru i vezom putem radio-talasa i sa veoma fleksibilnom arhitekturom. Mobilni sistem WiMAX koristi višestruki pristup frekvencijskoj ras- 
podeli kanala pomocu ortogonalnih nosilaca, OFDMA (Orthogonal Frequency Division Multiple Access), radi poboljšanja pojava koje karakteriše višestruko prostiranje talasa u uslovima bez postojanja opticke vidljivosti. Višestruki pristup skalabilnoj frekvencijskoj raspodeli kanala pomocu ortogonalnih nosilaca SOFDMA (Scalable Orthogonal Frequency Division Multiple Access) uveden je $u$ standard IEEE 802.16e radi podešavanja širine kanala od 1,25 MHz do $20 \mathrm{MHz}$.

Standard IEEE 802.16e definiše sve ono što je potrebno da zadovolji mobilni WiMAX sistem kako bi bio funkcionalan na multinacionalnom nivou gde je potrebno usaglasiti i najsitnije detalje pri ostvarivanju ovakvog komercijalnog i svima dostupnog bežic nog sistema.

Da bi sistemski profil bio u potpunosti funkcionalan, mora biti sertifikovan $\mathrm{i}$ interoperabilan (standardizovan). Mobilni sistemski profili omogucavaju mobilnim sistemima da budu fleksibilni po pitanju infrastrukture koja bi se koristila i koja bi uklju civala raznovrsne tipove terminala i baznih medusobno interoperabilnih stanica. Neki elementi profila vezani za bazne stanice bili bi opcioni da bi omogucili dodatnu fleksibilnost po pitanju zahteva, kao što su kapacitet, konfiguracija ili prostorna pokrivenost.

Prvi set mobilnog WiMAX standarda definisace širine kanala od 5,7 MHz, 8,75 MHZ i $10 \mathrm{MHz}$ na frekvencijama od 2,3 $\mathrm{GHz}, 2,5 \mathrm{GHz}$ i 3,5 GHz. Mobilni WiMAX sistemi nude rešenja vezana za tehnologiju radio-pristupa i mrežne arhitekture, uvažavajuci fleksibilanost u organizaciji mreže i ponudi servisa. Neke od istaknutih mogucnosti mobilnog WiMAX-a su:
- veliki protoci: uvodenje tehnologije MIMO antenskih sistema sa fleksibilnim upravljanjem spektralnim resursima koristeci SOFDMA, kao i unapreden sistem kodovanja koji omogucava najviši downlink (DL) protok od $63 \mathrm{Mb} / \mathrm{s}$, a uplink (UL) protok od $28 \mathrm{Mb} / \mathrm{s}$ po sektoru za kanal od $10 \mathrm{MHz}$;

- kvalitet servisa (QoS): najbitnija stavka IEEE 802.16, kontrola pristupa medijumu, MAC (Media Access Control) arhitekture je QoS (Quality of Service). QoS definiše servisne protoke koji mapiraju diferencijalni servis (DiffServ Differentiated Services) kodovne tacke ili MPLS (Multi Protocol Label Switching) labele koje omogucavaju IP (Internet Protokol) baziranu vezu s kraja na kraj. Još jedna pogodnost je potkanalizacija i MAP (Me dia Access Protokol) bazirana šema signalizacije koja omogucava fleksibilan raspored prostornih, vremenskih i frekvencijskih resursa na krajnjim interfejsima na bazi sistema „ram po ram";

- skalabilnost: uprkos velikom napretku globalne ekonomije, spektralni resursi širom sveta su i dalje ostali na istom nivou. Da bi se postigla harmonizacija korisnickih zahteva iskorišcavanja elektromagnetnog spektra na duži period, mobilni WiMAX koristi kanale od 1,25 $\mathrm{MHz}$ do $20 \mathrm{MHz}$. To omogucava bolje osmišljavanje strategije uvodenja ovog bežicnog sistema buducim provajderima, imajuci u vidu geografski položaj i kontradiktorne zahteve u pogledu pristupa internetu iz ruralnih sredina, nasuprot velikom opterecenju u urbanim sredinama;

- bezbednost: mogucnosti zaštite koje sadrži mobilni WiMAX najbolje su 
u klasi i sadrže EAP (Ex tensible Authentication Protocol) baziranu autentifikaciju, AES-CCM (Advanced Encryption Standard - Counter with Cipher-block chaining Message authentication code) baziranu autentifikovanu enkripciju i CMAC (block Cipher-based Message Authentication Code) i HMAC (keyed Hash Message Authentication Code) bazirane šeme zaštite kontrolnih poruka. Da bi se ove aplikacije mogle koristiti, potrebni su: pretplatnicki identifikacioni modul, SIM/USIM (Subscriber Identity Module/Username SIM) kartice, ,pametne" kartice, digitalni sertifikati i username/password nacin pristupa baziran na EAP (Ehtensible Authentication Protocol) metodama za autentifikovan pristup;

- mobilnost: mobilni WiMAX omogucava optimiziran handover (prelaz iz celije u celiju bez prekida veze) koji ne traje duže od $50 \mathrm{~ms}$. Zahvaljujuci ovakvom tipu handovera moguc je prenos glasa uz pomoc IP protokola, VoIP (Voice over IP) bez degradacije kvaliteta. Fleksibilna šema korišcenja kljuca omogucava zaštitu i tokom handovera [2].

\section{Opis fizickog sloja}

Osnove OFDM tehnike multipleksiranja

OFDM je tehnika multipleksiranja koja deli opseg od interesa na mnogo nosilaca (slika 1). Po OFDM tehnici, ulazni tok podataka podeljen je na nekoliko paralelnih tokova ciji je protok redukovan i svaki od njih se na poseban nacin moduliše i emituje po posebnom ortogonalnom nosiocu.

Povecanje trajanja simbola povecava otpornost OFDM na smetnje i kašnjenje. Šta više, uvodenje ciklicnog prefiksa, CP (Cyclic Prefix), u potpunosti može eliminisati pojavu intersimbolske interferencije sve dok je njegovo trajanje duže od trajanja vremena izmedu pristizanja dva ista simbola usled višestruke propagacije (delay spread). Ciklicni prefiks je obicno ponovljen poslednji deo bloka podataka (slika 2) koji je pridružen sle decem bloku podataka.

Ciklicni prefiks onemogucava interblok interferenciju, daje utisak da su kanali cirkularni i dozvoljava izjednacavanje $u$ frekvencijskom domenu radi manje složenosti

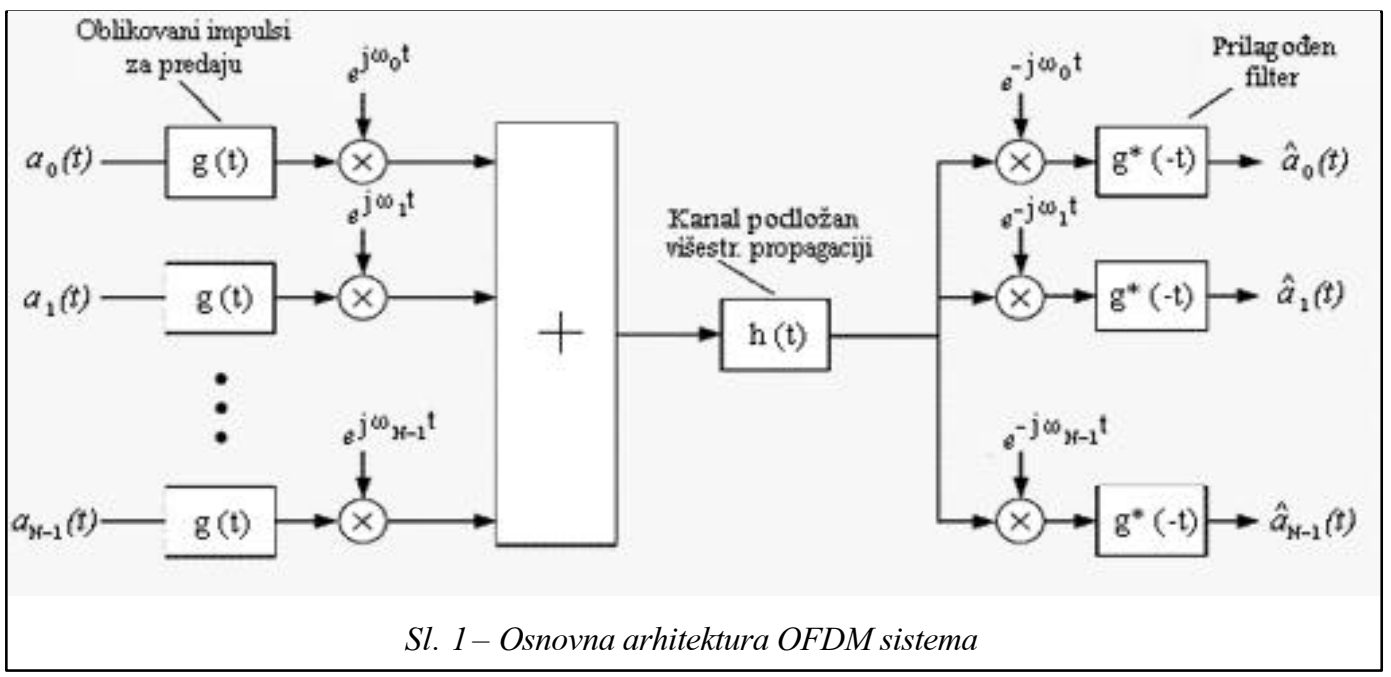




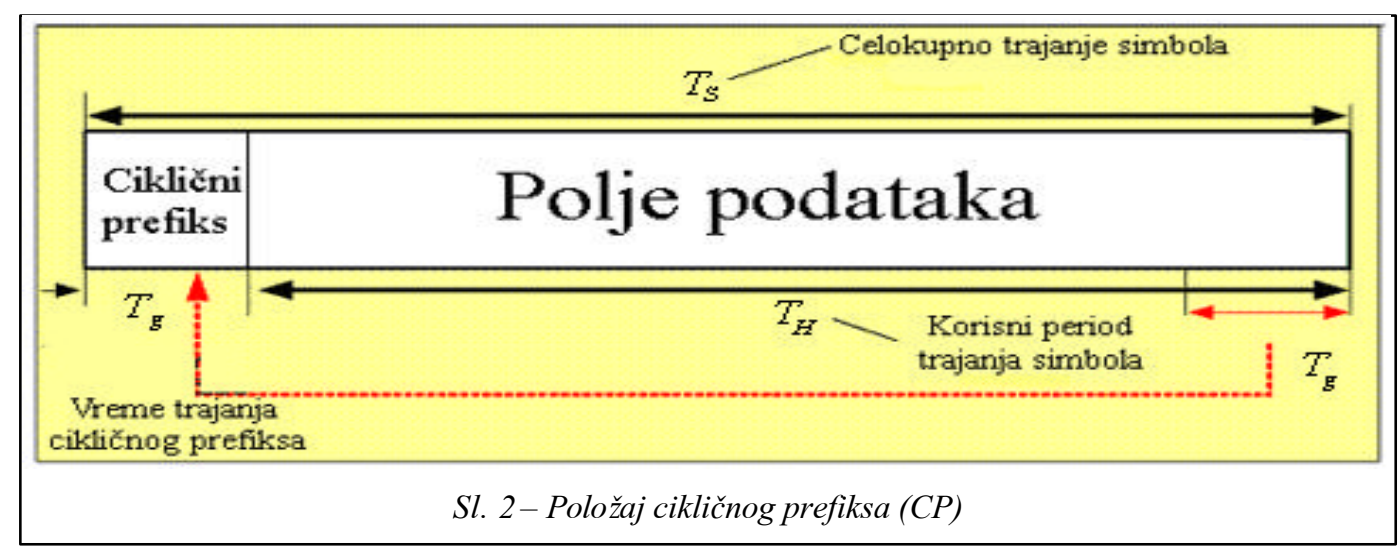

upotrebe frekvencija od interesa. Osnovna mana CP-a je smanjenost spektralne efikasnosti usled dodatka informacije. Bez obzira na ovu manu, uticaj CP-a je slican roll-off faktoru B u sistemima sa kosinusnim filterima i jednim nosiocem. Pošto OFDM ima oštar, skoro vertikalan spektar, ostatak slobodnog podrucja može se iskoristiti za prenos podataka koji se koriste radi poboljšanja efikasnosti ciklicnog prefiksa.

Da bi se prevazišlo višestruko prostiranje, kod OFDM tehnike koristi se interliving (,ucešljavanje“) i kodiranje. Modulacija se realizuje pomocu inverzne Furijeove transformacije na osnovu velikog broja potkanala koje koristi (2048). Resursi se eksploatišu kroz vreme u po- gledu OFDM simbola i kroz frekvenciju u pogledu podnosilaca. Oni se mogu podeliti po podopsezima da bi mogli biti dodeljeni razlicitim korisnicima.

OFDMA je tehnika multipleksiranja (višestrukog pristupa) koja obezbeduje operaciju slaganja više tokova podataka (streams) za više korisnika $u$ istom trenutku za downlink i uplink.

\section{Struktura OFDMA i potka nalizacija}

Struktura OFDMA sastoji se iz tri tipa podnosilaca, kao što je prikazano na slici 3:

- podnosioci koji nose informaciju;

- pilotski podnosioci za procenu stanja trase i sinhronizaciju;

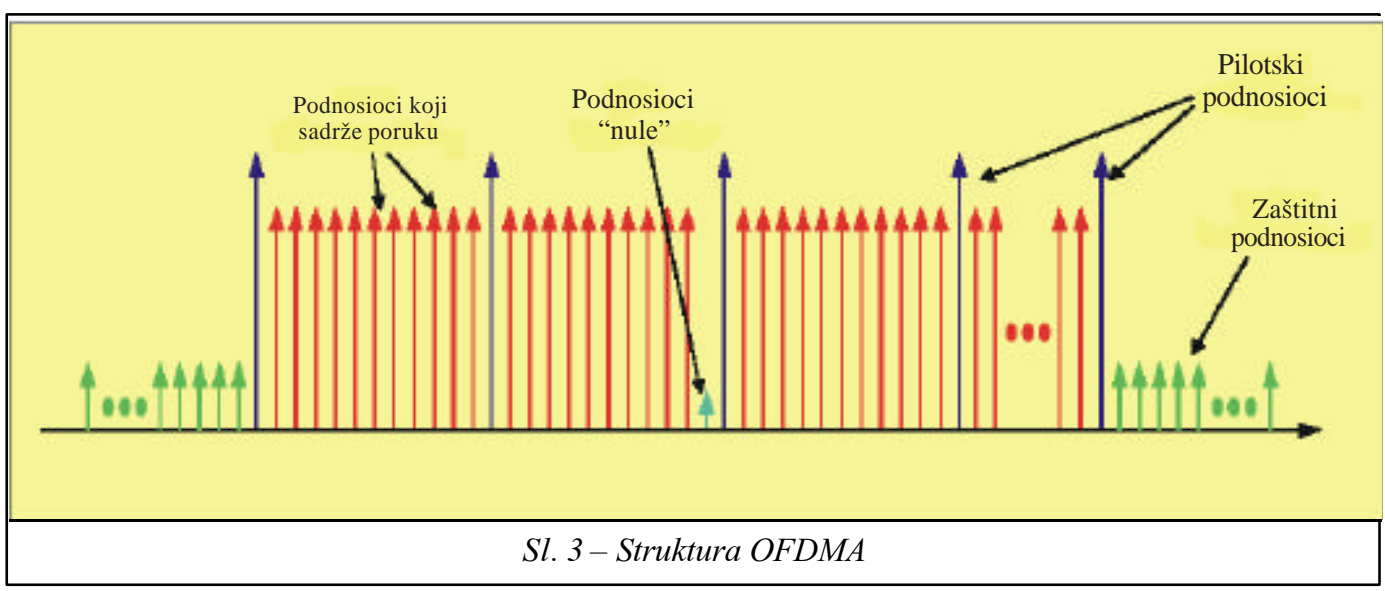


- podnosioci „nule“ koji služe za razdvajanje grupa informacionih kanala.

Aktivni podnosioci (informacioni i pilotski) grupisani su u potkanale. Fizicki sloj WiMAX OFDMA podržava potkanalizaciju i u uplinku i u downlinku [3].

Minimalna resursna jedinica potkanalizacije je jedan slot koji se sastoji od 48 informacionih podnosilaca. Postoje dva nacina grupisanja podnosilaca u potkanale - diverziti i granicna metoda.

Diverziti metoda rasporeduje podnosioce po potkanalima pseudoslucajno. Na taj nacin stvaraju se frekvencijski diverziti i ujednacavanje intercelijske interferencije. Diverziti permutacija sastoji se od DL FUSC (Fully Used Sub-Carrier - u potpunosti iskorišcen podnosilac), DL PUSC (Partially Used Sub-Carrier - delimicno iskorišcen podnosilac) i UL PUSC, ali sadrži i dodatne permutacije. Kod DL PUSC za svaki par OFDM simbola, raspoloživi i korisni podnosioci grupisani su u klastere, koji sadrže 14 granicnih podnosilaca po simbolu. Imaju razlicit razmeštaj pilota $i$ informacionih nosilaca u svakom od klastera odredenih na osnovu parnih i neparnih simbola.

Da bi se formirale grupe klastera koriste se šeme gde je svaka od grupa sacinjena od klastera rasporedenih u okviru opsega podnosilaca. Potkanal u grupi sadrži dva klastera, sacinjena od 48 informacionih podnosilaca i 8 pilotskih podnosilaca. Informacioni podnosioci svake grupe dalje su permutovani tako da stvaraju potkanale $u$ okviru grupe. Informacioni podnosioci u klasteru podeljeni su na vǐ̌e potkanala.

Analogno strukturi downlink klastera, definisana je struktura za UL PUSC. Raspoloživi opseg je raspodeljen na šest opsega izabranih iz citavog spektra na osnovu šeme rearanžiranja i permutacije koji cine slot.
Slot sadrži 48 informacionih podnosilaca i 24 pilota u 3 OFDM simbola [4].

Granicna permutacija grupiše podnosioce u blokove i na taj nacin stvara potkanale. Granicna šema permutovanja takode ukljucuje DL i UL adaptivnu modulaciju i kodiranje, AMC (Adaptive Modulation and Coding) i ima istu strukturu. Blok se sastoji od 9 kontinualnih podnosilaca po simbolu (8 informacionih i 1 pilot). Slot kod AMC definisan je kao skup blokova istog tipa $(\mathrm{NxM}=6)$ gde je $\mathrm{N}$ broj granicnih blokova, a $\mathrm{M}$ je broj granicnih simbola. Dozvoljene kombinacije su: 6 blokova i 1 simbol, 3 bloka i 2 simbola, 2 bloka i 3 simbola i 1 blok i 6 simbola. AMC dozvoljava diverziti ostvaren zahvaljujuci velikom broju raspoloživih kanala (Multi-user Diversity) birajuci kanal sa najboljim trenutnim karakteristikama.

Može se zakljuciti da su se diverziti permutacije pokazale boljima u slucaju mobilnih aplikacija, dok je granicna metoda permutacije bolja za upotrebu kod fiksne i sporopokretljive opreme [2].

Projekat IEEE 802.16e-2005 MAN (Metropolitan Area Network) OFDMA baziran je na koncepciji skalabilne OFDMA (SOFDMA), koja podržava širok spektar frekvencija, fleksibilnost adresiranja ucesnika i potrebe za razlicitim frekventnim podrucjima u elektromagnetnom spektru (EMS). Skalabilnost je postignuta podešavanjem velicine brze $\mathrm{Fu}$ rijeove transformacije, FFT (Fast Fourier Transform) razlicitim opsezima kanala radi svodenja na isti frekventni razmak izmedu nosilaca od 10,94 kHz. Pošto su širina kanala nosioca i trajanje simbola isti, uticaj na više nivoe ovako skaliranog opsega je manji. Parametri SOFDMA prikazani su u tabeli. Opsezi bitni za dva inicijalna profila su 5 i $10 \mathrm{MHz}$. 
Parametri SOFDMA

\begin{tabular}{|c|c|c|c|c|}
\hline Parametri & \multicolumn{4}{|c|}{ Vrednosti } \\
\hline Kanalska širina (MHz) & 1,25 & 5 & 10 & 20 \\
\hline $\begin{array}{c}\text { Frekvencija semplovanja } \\
\text { (Fp u MHz) }\end{array}$ & 1,4 & 5,6 & 11,2 & 22,4 \\
\hline Velicina FFT-a & 128 & 512 & 1024 & 2048 \\
\hline Broj potkanala & 2 & 8 & 16 & 32 \\
\hline Razmak izmedu nosilaca & \multicolumn{5}{|c|}{$10,94 \mathrm{kHz}$} \\
\hline $\begin{array}{c}\text { Vreme trajanja simbola } \\
\text { sa informacijom }\end{array}$ & \multicolumn{5}{|c|}{$11,4 \mathrm{~ms}$} \\
\hline Vreme razdvajanja & \multicolumn{5}{|c|}{$102,9 \mathrm{~ms}$} \\
\hline $\begin{array}{c}\text { Trajanje OFDMA sim- } \\
\text { bola }\end{array}$ & 48 \\
\hline $\begin{array}{c}\text { Broj OFDMA simbola } \\
\text { u frejmu od 5 ms) }\end{array}$ & \multicolumn{5}{|c|}{4} \\
\hline
\end{tabular}

\section{Struktura vremenskog multipleksa}

Fizicki sloj 802.16e standarda podržava TDD (Time Division Duplex), pun ili poludupleks FDD (Frequency Division Duplex). U kategoriji mobilnog WiMAX-a uzima se TDD kao jedino rešenje. Opciono ce FDD biti uveden za kori- snike u cijim zemljama regulativama nije obuhvacen TDD ili je korišcenje FDD-a prihvatljivije. Jedna od najbitnijih pretpostavki korišcenja TDD-a je opšta sinhronizacija sistema, ali, i pored takvih zahteva, TDD je pokazao preimucstvo nad FDD-om zbog sledecih osobina:

- TDD dozvoljava asimetricnost protoka uplink/downlink, dok FDD ima fiksni i u principu jednak protok po uplinku i downlinku;

- TDD obezbeduje reciprocnost kanala radi adaptiranja na trenutne uslove propagacije, što omogucuje MIMO i ostale tehnologije antenskih sistema;

- za razliku od FDD-a, kojem su potrebna dva kanala, TDD-u je potreban jedan kanal za downlink i uplink, što izuzetno olakšava adaptaciju na zahteve iskorišcenosti EMS-a;

- primopredajnici koji podržavaju TDD umnogome su jednostavnije konstrukcije od onih koji koriste FDD.

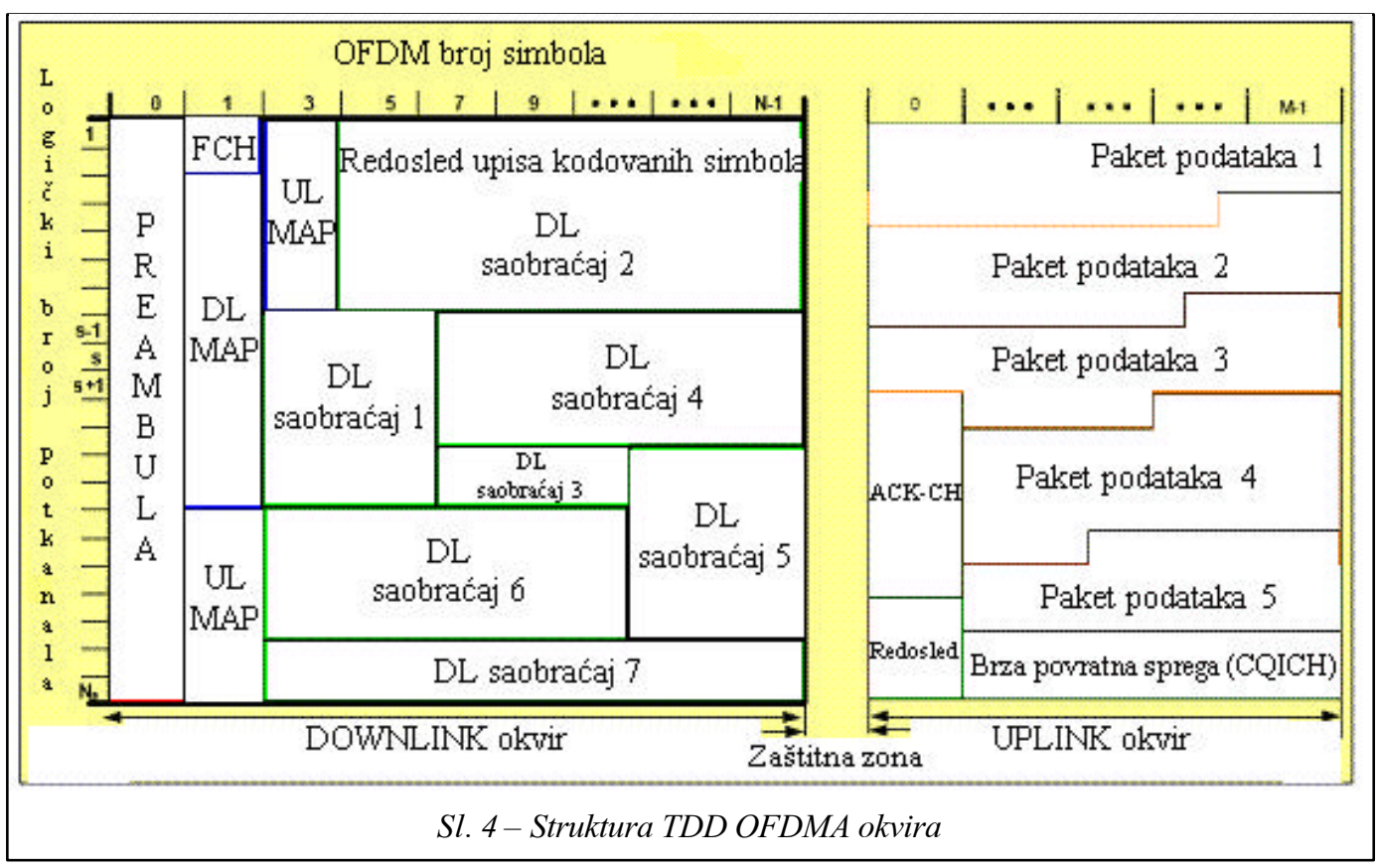


Slika 4 ilustruje strukturu TDD rama. Svaki ram je podeljen na DL i UL podramove razdvojene razmacima predaja/prijem i prijem/predaja koji sprecavaju medusobnu koliziju. Kontrolne informacije su deo rama koji obezbeduje optimalne uslove za opšte izvršavanje operacija. Cine ih:

- preambula, koja predstavlja prvi OFDM simbol rama i omogucava sinhronizaciju;

- zaglavlje za kontrolu rama (Frame Control Header - FCH), koje prati preambulu i nosi informaciju o dužini u protokolu za pristup medijumu, MAP (Me dia Access Protocol) poruke, šemi kodiranja i mogucnostima korišcenja nosilaca;

- DL-MAP i UL-MAP koji sadrže informaciju o dodeli nosilaca i drugim kontrolnim informacijama u DL i UL podramu, respektivno;

- UL ranging kanal koji je dodeljen mobilnoj stanici radi provere frekvencije, napajanja i potreba za opsegom;

- UL CQICH (Channel Quality Identification Control Header) kanal koji se dodeljuje mobilnoj stanici radi povratne informacije baznoj stanici o stanju kanala;

- UL ACK (Acknowledge), koji služi mobilnoj stanici za potvrdu primljene informacije.

\section{Ostale opcije i mogucnosti fizickog sloja}

Adaptivna modulacija i kodiranje, AMC (Adaptive Modulation and Coding), hibridni automatski zahtev za potvrdom prijema, HARQ (Hybrid Automatics Request) i brz izveštaj o stanju kanala (CQICH) neke su od mogucnosti mobilnog WiMAX-a, posebno važne za mobilne aplikacije.
HARQ je osmišljen tako da koristi „Stop and Wait" (zastani i pricekaj) protokol koji omogucava brzo ispravljanje paketskih grešaka i održavanje veze na ivici celije.

Saobracaj DL može koristiti kvadraturnu modulaciju sa faznim pomakom, QPSK (Quadrature Phase Shift Keying), kvadraturnu amplitudnu modulaciju 16QAM (Quadrature Amplitude Modulation) i 64QAM, dok je kod UL-a 64QAM opciona vrsta modulacije.

Konvolucioni kod (CC) i konvolucioni turbo kod (CTC) sa svojim mogucnostima promenljive kodne brzine takode su uklju ceni u mobilni WiMAX. $\mathrm{Na}$ osnovu plana bazne stanice (scheduler) za svakog korisnika posebno se sacinjava profil paketskog prenosa na osnovu velicine buffer memorije, uslova propagacije, vrste prijemnika, itd. Indikator kvaliteta kanala, CQI (Channel Quality Identification) koristi se radi planiranja ostvarivanja konekcije sa svakim korisnikom pojedinacno na osnovu informacije dobijene o stanju korisnic kog kanala. Mogucnost programiranja retransmisije medu baznim stanicama omogucava da se plan raspodele resursa na baznoj stanici rastereti. AMC podržava adaptaciju kanala i pri brzinama od $120 \mathrm{~km} / \mathrm{h}$, što predstavlja dodatnu opciju.

\section{Opis sloja za kontrolu pristupa medijumu MAC (Media Access Control)}

Standard 802.16 razvijen je kao polazna osnova za omogucavanje širokopojasnih servisa, kao što su prenos glasa, podataka i pokretne slike. Sloj MAC ba- 
ziran je na specifikaciji usluga prenosa podataka preko kabla, DOCSIS (Dataover-Cable Service Interface Specifications) standardu i dozvoljava paketski prenos podataka sa veoma velikim protokom. Istovremeno je omogucen prenos pokretne slike i govora osetljivog na kašnjenje po istom kanalu.

Resursi koje MAC plan raspodele dodeli terminalu mogu varirati od jednog vremenskog slota do citavog frejma, omogucavajuci korisnicima veoma velik i dinamican opseg protoka, u zavisnosti od potreba terminala u odredenom trenutku. S obzirom na to da se informacija o zahtevanim resursima nalazi na pocetku svakog frejma (rama), plan raspodele može uspešno promeniti dodelu resursa na „frame-by-frame“ (frejm po frejm) bazi, da bi adaptirao saobracaj kako ne bi došlo do zagušenja.

\section{Kvalitet servisa (QoS)}

Pošto kanali mobilnog WiMAX-a imaju velike brzine protoka, simetrican downlink/uplink kapacitet i fleksibilan mehanizam dodele resursa korisnicima, sa sigurnošcu se može tvrditi da se QoS uslovi mogu ispuniti u širokoj oblasti servisa i aplikacija.

Kod mobilnog WiMAX-a QoS je izveden kroz sam tok servisa. To je neupucen tok paketa podržanih pojedinim QoS parametrima. Pre odlucivanja za konkretan tip servisa, bazna stanica i korisnicki terminal, uz pomoc svojih MAC slojeva, ostvaruju neupucen logicki link - konekciju. Zatim se, uz pomoc bazne stanice, uspostavlja paketski prenos u vidu toka servisa koji biva dostavljen korisniku preko konekcije. Parametri QoS, vezani za tok podataka, definišu pravila transmisije i plana raspodele interfejsa za radio-vezu. Usmereni na konekciju oni upravljaju ovim interfejsom. Pošto radio-interfejs po svojim opštim karakteristikama predstavlja usko grlo, QoS parametri konekcije uspešno omogucavaju kontrolu kvaliteta veze s kraja na kraj. Parametri toka servisa se u toku veze uspešno mogu adaptirati na dinamicne promene zahvaljujuci MAC porukama. QoS baziran na toku servisa kontroliše kvalitet uplink-a i downlink-a respektivno.

Da bi se uspešno uporedile tri tehnologije kao što su mobilni WiMAX, GSM povecanog kapaciteta sa novim standardi-
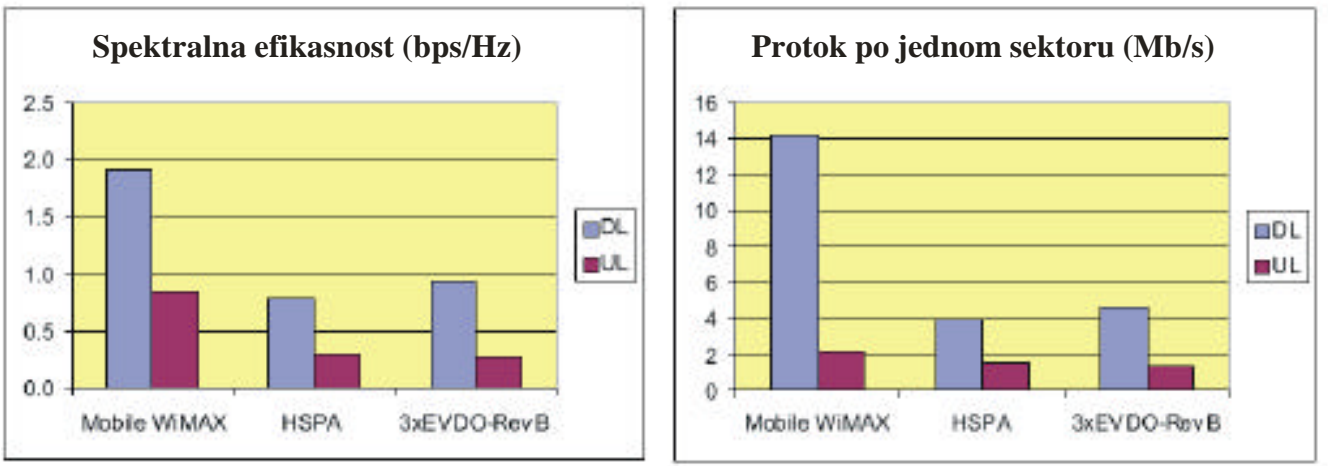

Sl. 5 - Poredenje spektralne efikasnosti i protoka pojednom sektoru HSPA, EVDO-Rev B i mobilnog WiMAX-a pod istim uslovima saobra caja 
ma i GSM sa pristupom paketima velike brzine HSPA, izvršeno je poredenje propusne moci i spektralne efikasnosti na osnovu uobicajenog seta parametara.

Slika 5 pokazuje da mobilni WiMAX ima odredene prednosti nad $3 \mathrm{G}$ mobilnim sistemima u pogledu spektralne efikasnosti i propusne moci, kako u DL-u, tako i u UL-u [2]. Spektralna efikasnost za jedan telefonski kanal opsega $3 \mathrm{kHz}$ kod WiMAX iznosi $5,7 \mathrm{~kb} / \mathrm{s}(3000 \mathrm{~Hz} \times 1,9$ bps/Hz), dok kod 3 x EVDO-Rev B iznosi $2,7 \mathrm{~kb} / \mathrm{s}(3000 \mathrm{~Hz}$ x 0,9 kps/Hz).

\section{Zakljucak}

Za razliku od $3 \mathrm{G}$ sistema baziranih na CDMA, koji su namenjeni iskljucivo za prenos govora, mobilni WiMAX omogucava prenos široke palete ostalih širokopojasnih servisa, kao što su podaci, pokretna slika i dr. Visoki protoci omogucavaju bolje multipleksiranje i manje kašnjenje, što je neophodno radi kvalitetnog prenosa govora (VoIP). Ovakvim karakteristikama mobilni WiMAX pruža isti kvalitet usluga kao i kablovski ili DSL (Digital Subscriber line) pristup, tako da omogucava servis, kao što je real-time interaktivno delovanje, što je vrlo bitno sa aspekta komandovanja u kriznim situacijama.

Fizicki sloj mobilnog WiMAX sistema baziran je na OFDMA tehnologiji. Ovakav nacin ostvarivanja modulacije i multipleksiranja, pored male složenosti, omogucava i:

- otpornost na višestruko prostiranje $\mathrm{i}$ interferenciju;

- skalabilan opseg kanala;

- ortogonalan višestruki pristup u uplinku;
- podrža vanje spektralno vrlo efikasnog TDD;

- plansko rasporedivanje frekvencija u upotrebi;

- dobar kvalitet servisa (QoS);

- naprednu tehnologiju izrade antenskih sistema.

Da bi sistem veza mogao da funkcioniše u vanrednim prilikama i u ratu, moraju im se obezbediti neophodni i realni uslovi u okruženju i unutar sistema. Osnovni uslov je pravilno odreden i definisan cilj koji se želi postici funkcionisanjem tog sistema. Složeni sistemi, kakav je sistem veza, imaju kompleksne ciljeve. Sistem mora imati punu potvrdu okruženja o neophodnosti postojanja i uspešnog funkcionisanja. U protivnom, ne bi opstao.

Bitan uslov je da sistem veza svojom organizacijom i funkcionisanjem zadovolji princip prilagodljivosti sa drugim sistemima koji izvršavaju slicne funkcije. Kompatibilnost sistema obezbeduje njihovo medusobno povezivanje, otklanjanje pojedinacnih propusta i dopunjavanje funkcija.

$\mathrm{Na}$ osnovu dosadašnje analize dva vrlo slicna sistema dolazi se do zakljucka da je neophodno da se Srbija, kao zemlja u tranziciji, opredeli za najkvalitetniji i najjeftiniji nacin modernizacije svog sistema veza. U pogledu samih karakteristika, mobilni sistem $3 \mathrm{G}$, koji je hipoteticki kod nas vec zaživeo, pruža veoma kvalitetne servise koji bi se mogli uspešno eksploatisati kako u redovnim, tako i u vanrednim situacijama. Nasuprot nedovršene celokupne infrastrukture ovog sistema u zemlji, kao rešenje namece se uvodenje mobilnog sistema WiMAX koji bi rešio problem dostizanja potrebnog nivoa bežicnog ostvarivanja vrlo sigurnih veza, na širokim prostranstvima, gde nije potrebna ka- 
blovska infrastruktura. Sagledavši sve aspekte samih karakteristika oba sistema, može se zakljuciti da WiMAX pruža bolje mogucnosti. Zato bi bilo potrebno da mobilni WiMAX, kao zajednicko rešenje za mobilne i fiksne ucesnike, na širokom prostoru putem radio-talasa i sa veoma fleksibilnom arhitekturom, pruži potreban znacaj sistemu veza.

\section{Literatura:}

[1] Lazarevic, M.: Organizaci ja sistema veza u državnoj zajednici Sibija i Cma Gora, Vojna akademija, Beograd, 2006.

[2] Mobile Wi MAX - Part I: A Technical Overview and Performance Evaluation, WiMAX Forum, 2006.

[3] Yagoobi, H.: Scalable OF DMA Physical Layer in IEEE 802.16 Wireless MAN, Intel Technology Journal, Vol 08, 2004.

[4] Stojanovic, M.; Lazovic, S.: Implementacija kvaliteta servisa u multiservisnim IP mrežama, Zbornik radova PosTel 2004, Beograd, 2004.

[5] WiMAX Forum,

Applications for 802.16-2004 and 802.16e_WiMAX

_networks_final, 2005.www.wimaxforum.org 